\title{
ASSESSMENT OF AZOLE RESISTANCE IN CLINICAL SETTINGS BY PASSIVE SAMPLING
}

\section{A. Caetano ${ }^{1,2}$, B. Almeida ${ }^{1}$, C. Viegas $^{1,3}$}

\& Technology Research Center, ESTeSL- Escola Superior de Tecnologia da Saúde, Instituto Politécnico de Lisboa; ${ }^{2}$ Research Institute for Medicines (iMed.ULisboa), Faculty of Pharmacy, University of Lisbon, Lisbon, Portugal; ${ }^{3}$ Centro de Investigação em Saúde Pública, Escola Nacional de Saúde Pública, Universidade NOVA de Lisboa liliana.caetano@estesl.ipl.pt

\section{INTRODUCTION}

Clinical settings (hospitals, primary health care centers - PHCC), with high occupation rates, present microbiologic agents in their environment. Exposure to mycobiota in indoor environments is related to several adverse human health effects, such as respiratory symptoms. ${ }^{1}$

Azole resistance in fungal species and consequent failure of antifungal therapy are a major concern for public health. ${ }^{2}$ Portuguese legislation recommends active air sampling for bioburden assessment indoor. Passive sampling can be used in complement to determine bioburden levels from longer periods. ${ }^{3}$

AIM: To assess the fungal burden and prevalence of azole resistance in clinical settings in Portugal using passive sampling methods.

\section{MATERIALS AND METHODS}

I. Ten Portuguese Primary Health Care Centers (PHCC) were sampled between June and September 2018 by passive sampling:

- Electrostatic dust cloths (EDC) - in place for 15 days

- Heating Ventilation and Air Conditioning (HVAC) - equipment filters

- Settled dust - 10 minutes vacuumed

II. Samples seeded onto azole- supplemented Sabouraud dextrose agar (SDA) supplemented with $4 \mathrm{mg} / \mathrm{L}$ itraconazole (ITRA), $1 \mathrm{mg} / \mathrm{L}$ voriconazole (VORI), or $0.5 \mathrm{mg} / \mathrm{L}$ posaconazole (POSA).

III. Fungal count and identification after 5 days incubation at $27^{\circ} \mathrm{C}$.

\section{RESULTS}

TOTAL FUNGAL BURDEN PER PHCC PER SAMPLING Fungal load (SDA):

- EDC -348 to 424628 CFU. $m^{-2}$

- HVAC - 0 to 56500 CFU.m ${ }^{-2}$

- Settled dust - 2 to 514 CFU.g-g

FUNGAL GROWTH IN THREE AZOLES

- EDC-4 PHCC

- HVAC- 2 PHCC

- Settled dust-1 PHCC

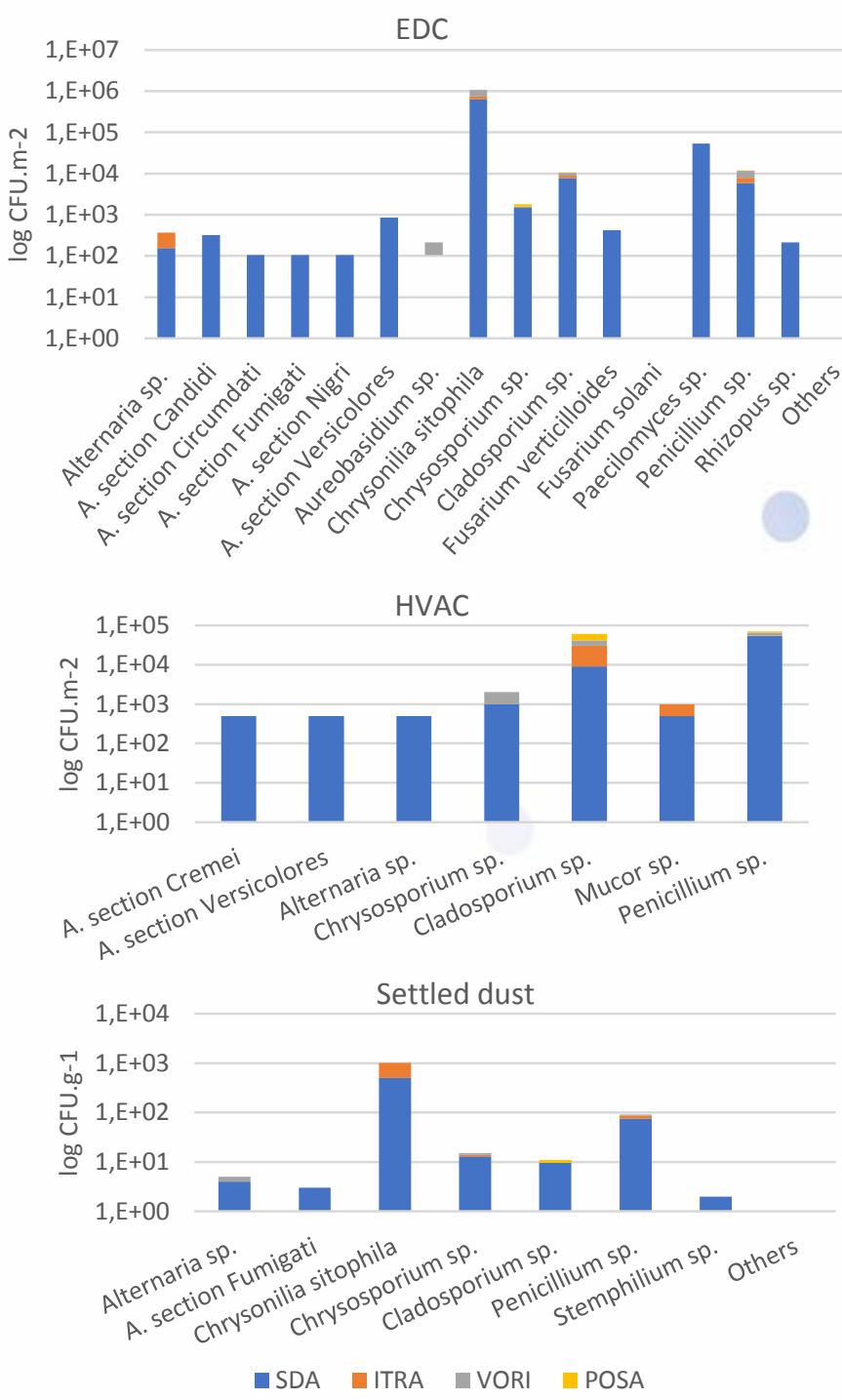

Fungal growth in $>1$ azole in $9 / 10$ PHCC for:

- Penicillium sp.

- C. sitophila

- Cladosporium sp.

No azole resistance found for Aspergillus sp.

\section{CONCLUSIONS}

- Passive sampling enables an accurate characterization both quantitative and qualitative of total and azole-resistant fungal burden. ${ }^{3}$

- Passive sampling should be included in sampling protocols in the assessment of total and azoleresistant bioburden in clinical settings.
Acknowledgements to FCT Fundação para Ciência e Tecnologia for funding the project EXPOsE Establishing protocols to assess occupational exposure to microbiota in clinical settings (02/SAICT/2016 - Project no 23222). 